\title{
Parents' Nonstandard Work Schedules and Adolescent Social and Emotional Wellbeing
}

Jianghong Li, PhD ${ }^{1,2,3 *}$, Hannah Kenyon Lair ${ }^{1}$, Jakob Schäfer, M.S. ${ }^{1,4}$, Garth Kendall, $\mathrm{PhD}^{3}$

1. WZB Berlin Social Science Center, Berlin, Germany

2. Telethon Telethon KIDS Institute, The University of Western Australia

3. Curtin University, Perth, Western Australia

4. Hannah-Arendt-Gymnasium Berlin, Berlin, Germany (at present)

*Corresponding author: Jianghong Li, WZB Berlin Social Science Center, Reichpietschufer 50, 10785 Berlin, Germany; Tel: +49 3025491 564; Email: jianghong.li@wzb.eu

\section{Acknowledgements}

We would like to acknowledge the Raine Study participants and their families for their ongoing participation in the study and the Raine Study team for study co-ordination and data collection. We also thank the National Health and Medical Research Council (NHMRC) for their long-term contribution to funding the study over the last 30 years. The core management of the Raine Study is funded by the University of Western Australia, Curtin University, Telethon Kids Institute, Women and Infants Research Foundation, Edith Cowan University, Murdoch University, The University of Notre Dame Australia, and the Raine Medical Research Foundation.

The Gen2-14 year follow-up was funded by NHMRC Grant 211912, NHMRC Program Grant 003209, and the Raine Medical Research Foundation. The Gen2-17 year follow-up was generously funded by NHMRC Program Grant 353514.

We gratefully acknowledge Dr. Manuel Bosancianu for his statistical advice on testing and addressing the issue of heteroscedasticity.

We declare that none of the authors has conflict of interest.

\section{Parents’ Nonstandard Work Schedules and Adolescent Social and Emotional Wellbeing}


Increasing evidence shows that parents’ work schedules in evenings/nights have a negative impact on children’s physical and mental health. Few studies examine adolescents and joint parental work schedules. We investigate the association between joint parental work schedules and adolescent mental health and test parental time spent with adolescents and parenting style as potential mediators.

We analysed one wave of the Raine Study data, focusing on adolescents who were followed up at ages 16-17 and lived in dual earner-households $(\mathrm{N}=607)$. Adolescent mental health is measured in the Child Behavioural Checklist (morbidity, internalising behaviour, externalising behaviour, anxiety/depression). Parental work schedules were defined as: both parents work standard daytime schedules (reference), both parents work evening/night/irregular shifts; fathers work evening/night/irregular shifts - mother day schedule, mothers work evening/night/irregular shifts - father daytime schedule. Compared to the reference group, when one or both parents worked evening/night/irregular schedules there was a significant increase in total morbidity, externalizing behavior and anxiety/depression in adolescents. Fathers’ evening/night/irregular schedule was associated with a significant increase in total morbidity and externalizing behavior. Inconsistent parenting partially mediated this association. Mothers’ evening/night/irregular schedule was not associated with adolescent CBCL scores. Our findings underscore the importance of fathers’ work-family balance for adolescent mental health.

Key words: evening/nights/irregular shifts, parental joint work schedules, adolescent mental health, social and emotional wellbeing, the Raine Study. 


\section{Parents’ Nonstandard Work Schedules and Adolescent Social and Emotional Wellbeing}

Under rapid social, economic, and technological transformations and globalization, we work increasingly longer hours in paid employment (Messenger, 2018) and nonstandard work schedules (evenings, nights, weekends, irregular shifts). Research to date has documented a high prevalence of nonstandard work (NSW here onwards) schedules in developed economies (Australian Bureau of Statistics (ABS), 2009; Kaiser et al., 2019; McMenamin, 2007).

Extensive evidence has shown that NSW schedules (e.g., evening and night shifts) has a detrimental impact on workers’ health (Kantermann et al., 2010; Moreno et al., 2019). Emerging research demonstrates that this impact extends to children whose parents work NSW schedules (Li et al., 2014). Children whose parents work NSW schedules are at increased risk of social and emotional problems. This negative impact is partially mediated through poor parental mental health (Strazdins et al., 2006), low quality parenting (Han et al., 2010; Kaiser et al., 2019; Rosenbaum \& Morett, 2009) and reduced parent-child interaction (Han et al., 2010).

Our study is motivated by two theoretical perspectives: the family and community resource framework (BrooksGunn et al., 1995; Kendall \& Li, 2005) and work-family conflict theory (Bakker et al., 2008; Greenhaus \& Beutell, 1985). Brooks-Gunn and colleagues identified four categories of intra-familial resources that are important for optimal child development (Brooks-Gunn et al., 1995): income, time, human capital, and psychological capital (e.g., parents’ mental health). Parents’ NSW schedules can influence children’s wellbeing through these familial resources. For example reduced child-parent interaction and closeness underpin the link between parents’ NSW schedules and increased risk for social and emotional problems in American children (Han et al., 2010; Han \& Miller, 2009; Rosenbaum \& Morett, 2009). Depressive symptoms in parents have been found to partially mediate the negative impact of NSW schedules on Canadian children's mental health (Strazdins et al., 2006). One plausible explanation for this mediation effect is that depressed parents may be less engaged with children or interact with children with less affection and closeness. This suggests that the time 
parents spend with their children and the way they interact with their children (parenting behaviour) both play a significant role in the association between NSW schedules and child or adolescent health. Kaiser and colleagues have shown that both mothers' and fathers' evening/night work schedules are associated with an increase in children’s externalizing and internalizing behavior and harsh and strict parenting in part mediated this association (Kaiser et al., 2019).

Work-family conflict occurs due to time, energy, and behavioural constraints and a psychological carryover of strains from work to family life (Greenhaus \& Beutell, 1985) or vice versa. NSW schedules increase the risk of work-family conflict because they negatively impact worker's mental and physical health and reduce their capacity to cope with both work and family demands (Dhaini et al., 2018; Moreno et al., 2019). Stress, fatigue and sleep deprivation associated with working NSW schedules likely diminish the amount and quality of time parents spend with their children and also lower the quality of parenting and interaction with children.

Despite consistent evidence for negative effects of parental NSW schedules on young children (Li et al., 2014), relatively few studies have examined the association between NSW schedules and adolescent health (Dockery et al., 2009; Dockery et al., 2016; Han et al., 2010; Han \& Miller, 2009). Adolescents are at greater risk of anxiety and depression than young children (Andersen \& Teicher, 2008). They have a high incidence of suicide (Andersen \& Teicher, 2008) and risk-taking behaviour (e.g., excessive alcohol consumption and substance use) (Squeglia et al., 2009). Adolescence represents a critical developmental stage where extensive neurobiological, psychological, and physical changes continue to take place (Pokhrel et al., 2013; Squeglia et al., 2009). Adolescents face significant challenges related to developing social and sexual identity, making school to school and school-to-work transitions, forming intimate relationships, and dealing with peer pressures (Lawrence, 2005). Hence adolescents still need a great deal of support from parents.

Over 80 \% of adolescents live in two parent families in Australia (Australian Bureau of Statistics (ABS), 2019), and it is important to consider the work schedules of both parents. Few studies have examined the interaction 
between fathers' and mothers’ NSW schedules (Han, 2020; Kaiser et al., 2019). The degree to which the work schedules of parents in dual-earner families overlap has important implications for parental relationships, the division of household labour, and parental participation in children's activities, all of which may influence children's health and developmental outcomes. None of the four studies on the association between parental work schedules and adolescent mental health, to date, have considered the interaction between fathers' and mothers’ NSW schedules (Dockery et al., 2009; Dockery et al., 2016; Han et al., 2010; Han \& Miller, 2009).

In this study we used data for families residing in Western Australia to examine the association between joint parental NSW schedules and the mental health of adolescents and test the hypotheses that parental time spent with adolescents and parenting style mediate this association.

\section{Methods}

\section{Study sample}

We analyzed the data from the Raine Study, a prospective cohort study of 2,868 live births followed from 18 weeks gestation. More detailed information on the Raine Study recruitment and method has been documented elsewhere (Newnham et al., 1993). The primary caregiver (mostly mother) and the child were followed up at birth, and at ages one, two, three, five, eight, 10, 14, 17, 20, 22, and 27 years. The Raine study represented the broader Western Australian population at every wave (Straker et al., 2017). The Raine Study protocol was approved by the Human Research Ethics Committees at King Edward Memorial Hospital and Princess Margaret Hospital for Children in Perth.

This study used only data from the $9^{\text {th }}$ follow-up, when the children were aged $16-17$ years, because this is the only follow-up at which information on parent work schedule was collected. As we are interested in joint parental work schedules and its association with adolescent mental health, our study sample consisted 662 participants (adolescent children) living in both-parent families. The final effective sample for multivariate 
models included 607 adolescents with no missing data on the outcome variables and main predictors or any covariates.

\section{Measures}

\section{Dependent variables}

Adolescent mental health was measured by the Child Behavioral Checklist (CBCL), developed by Achenbach (Achenbach \& Edelbrock, 1991). The CBCL is intended to measure variability in child and adolescent behavior in a nonclinical population. It demonstrated good test-retest reliability, good sensitivity (83\% overall), and reasonable specificity (67\% overall) (Zubrick et al., 1997). The CBCL scores included total morbidity, internalizing and externalizing behavior, anxiety and depression. Adolescents and their primary caregivers answered the CBCL questionnaires from which these four scores were derived. We analyzed two sets of four CBCL scores: parent-reported and adolescent-reported.

Three common variations on CBCL scores are: raw scores, t-scores, and z-scores; raw scores and t-scores are available in the Raine Study data. Raw scores are the unadjusted scores from the CBCL questionnaires included in the Raine Study. Achenbach (Achenbach \& Edelbrock, 1991) recommends using raw scores because they are often “more precise and uniform than t-scores” at the high end of the distribution (Achenbach \& Edelbrock, 1991, p. 190). T-scores are age standardized scores with mean 50 and standard deviation 10 . This score is recommended if gender differences are not controlled for, or if respondent age differences are non-trivial. This study met neither of these criteria. We controlled for gender and our sample has a narrow age range within 1-2 years. Additionally, the t-scores for externalizing and internalizing behaviors have been truncated at 50 such that t-score values below 50 are computed as 50 (Achenbach \& Edelbrock, 1991, p. 190). This reduces variation at the low end of the distribution, which would have been an unnecessary drawback for our analysis. The zscores are standardized with mean 0 and standard deviation 1 . They reduce variation by collapsing point-based scores into a much smaller scale. They are useful for comparing scores between different groups or populations. 
Because our analysis did not involve such comparison, it was not necessary or desirable to use z-scores. Thus, we followed Achenbach’s recommendation and analyzed raw scores in our analysis.

\section{Independent variables}

The main predictor was joint work schedules for the main job of both parents. They were coded as: both parents worked regular daytime schedules (reference); both parents worked evening/night/irregular shifts; only fathers worked evening/night/irregular shifts; only mothers worked evening/night/irregular shifts. For the last two categories, the other parent worked regular daytime shifts.

\section{Mediating variables}

We examined two plausible mediators that link parents’ NSW schedules to adolescents’ mental health: parental time spent with adolescents on weekends (none, 1-2 hours; 3-4 hours, 5-6 hours; 7 or more hours), and parenting style. These variables were non-interval ordinal indicators, which are not suitable for summation. Thus, we tested each of these items individually. The questions on parenting was answered by the primary care provider for the child in the home (mostly the mother). The parenting style scale in the Raine Study was drawn from the Lempers Parenting Questionnaire, with Cronbach's alpha of 0.80 and good construct validity (Lempers et al., 1989). We tested two parenting style indicators (inconsistent parenting and nurturing parenting) from this parenting scale. The items were on a four-point Likert scale (from 0 Never to 3 Very Often). Inconsistent parenting included such items: parent soon forgets a rule they have made; nags about little things; threaten punishment more often than they use it; threaten or hit child, enforce rules only when it suits them, and enforce rules only depending on their mood. Nurturing parenting included these items: smile at child; praise child; tell child they appreciate them; speak of good things child does; and seem proud of child. The inconsistent and nurturing parenting styles were constructed by taking the mean rather than the sum of the numeric value of each item (between 0 and 3) because both parenting scales had different numbers of items.

\section{Co-variates}


We controlled for mother's education, mothers' ethnicity, and both parents' occupations as previous research has shown that these variables are associated with both adolescent mental health (British Medical Association, 2006) and with working NSW schedules (McMenamin, 2007; Presser, 2003), thus potentially confounding the effect of parental NSW schedules on adolescent mental health. Due to a large number of missing cases for fathers’ education, only mothers’ education was controlled for, and it was a categorical variable indicating highest completed educational qualification: primary, secondary or higher. Parents’ occupation was coded as: Manager, professional, paraprofessional, clerical or sales, trade, plant operator or labourer. Maternal ethnicity was a dichotomous indicator (Caucasian vs other). Parent work hours were also controlled for because long working hours of fathers has been shown to affect child behavioral problems (Johnson et al., 2013) and long work hours may spread to evenings, nights or weekends. We also controlled for maternal age, child gender, child birth weight, and substance use in the household, including smoking. Maternal age was coded as: 14-24 (reference), 25-29, 30-34, 35 or older. Child gender and substance use were dichotomous indicators.

\section{Analytic strategy}

We used a linear regression model to analyze the association between parents’ NSW schedules and parentreported and adolescent-reported CBCL raw scores for total morbidity, internalizing and externalizing behaviors, and anxiety-depression. As the CBCL scores were skewed and kurtotic (Appendix 1), we first tested for heteroskedasticity of residuals using the Breusch-Pagan test (Breusch \& Pagan, 1979). The test indicated heteroskedasticity. To solve this problem, we used log-transformation of the CBCL scores. The Breusch-Pagan test was re-run using the log-transformed CBCL scores and the normality assumption was met for total morbidity, internalizing and externalizing scores, but heteroskedasticity to some extent remained for anxiety/depression. Thus, we used Huber-White Robust standard errors for analyzing log-transformed anxiety/depression scores.

\section{Mediation analysis}


The mediation analysis proceeded along three steps: 1) testing for possible mediation effect; 2) estimating the effect sizes; and 3) estimating confidence intervals. First, we tested for initial evidence of mediation effect (Baron \& Kenny, 1986) by estimating linear regression models including all covariates, without and with each mediator. The initial evidence of mediation is a reduction of the effect size or statistical significance of the effect of parent work schedule on CBCL scores in the model including the mediator in comparison with the model excluding the mediator. For mediators that showed this initial evidence of mediation, we estimated the magnitude of the indirect, direct, and total effects using the general linear modelling approach to estimating mediation effects in models with a categorical independent variable (Preacher \& Hayes, 2008). This approach is operationalized in STATA using the seemingly unrelated regression and non-linear combination of estimates tools.

Using these STATA tools, we estimated mediation effect sizes with the four-categorical joint parent work schedule variable and the dichotomous parent work schedule variable ( 1 = one or both parents worked NSW schedule; 0 = neither parent worked NSW schedule). We tested for mediation effects with the collapsed work schedule variable in order to maximize statistical power as some of the NSW schedule categories have small cells. This allowed us to see whether any mediation effects were obscured when using the multi-categorical indicator due to reduced statistical power. To estimate confidence intervals and significance levels for these effects, we used the resampling method of bootstrapping with bias-corrected confidence intervals (Hayes, 2013), with 1000 iterations. This is the most robust approach as it minimizes downward bias in mediation effect estimation (Hayes \& Scharkow, 2013).

\section{Post-hoc analysis}

We tested for an association between parent work schedule at age 16/17 and child behavioral outcomes at age 13/14 to address the possibility of a reverse causal relationship: child behavioral problems led to parent NSW schedules. 


\section{Results}

\section{CBCL scores}

For parent-reported CBCL scores, the mean score for total morbidity is much higher than those for externalizing behavior, internalizing behavior, and anxiety/depression which has the lowest mean value (Table 1). Parentreported CBCL scores are highly skewed towards the low end of the scale for total and all three subdomain scores, whereas adolescent-reported CBCL scores (Appendix 1) are much less skewed for internalizing behavior and anxiety-depression with a wider range, and moreover the scores for total morbidity and externalizing behavior show almost a normal distribution. These differences may suggest that parents might be unaware of all mental health issues which adolescent children were confronted with.

\section{Parent NSW schedules}

In $50 \%$ of adolescents, either the mother or the father worked NSW schedules (evening, night, rotating, irregular, variable, on-call, or weekends). Of this, about $11 \%$ adolescents lived in the households where both mothers and fathers worked NSW schedules, $22 \%$ where only mothers worked NSW schedules, and about $17 \%$ where only fathers worked such schedules.

\section{NSW schedules and parent-reported CBCL scores}

Table 2 shows that having one or both parents who worked NSW schedules was associated with higher scores for total morbidity, externalizing and anxiety/depression. When breaking down the dichotomy of NSW schedule into four categories reflecting joint parent work schedules, we observed that: 1) having both parents work NSW schedules was associated with higher CBCL scores, but this association was not significant; 2) fathers' NSW schedules combined with mothers' standard schedules were associated with higher scores for total morbidity and externalizing behavior; 3) these associations were independent of parents' total work hours, parental education and occupation, and adolescent birth weight and gender. Mothers' NSW schedules with fathers' standard schedules were not significantly associated with adolescent CBCL scores. In further analysis we 
examined possible interactions between adolescent gender and NSW schedules but the results were not significant.

\section{Mediation effects}

Tables 3 shows only the results for CBCL scores for which there was initial evidence of mediation in the first step of the testing procedure as described in the methods section. In Table 2 we observed that fathers' NSW schedules were associated with higher scores for total morbidity and externalizing behavior. Table 3 shows that inconsistent parenting was associated with higher total CBCL scores (b-0.30, p<0.01) and also partially mediated the effect of fathers' NSW schedules on total morbidity $(b=0.04, p<05)$. None of the results from the tests of parental time spent with adolescents as mediators was significant. When using parent NSW schedules as a dichotomy (Appendix 2: Table 3), while parental time spent with adolescents on weekends was associated with higher total and externalizing scores, it did not mediate the effect of NSW schedules on the outcome variables. This suggests that the association between having one or both parents working NSW schedules and all CBCL scores, observed in Table 2, are primarily direct effects.

\section{Reverse Causality Check}

There was a significant bivariate correlation between CBCL scores at the previous follow-up (age 13-14) and parent work schedules at age 16-17. However, the statistical significance disappeared when we adjusted for the same socioeconomic and demographic co-variates as in the main models. Hence the likelihood of a reverse causal effect of child CBCL score on parents’ NSW schedules is unlikely.

\section{Results based on adolescent-reported CBCL scores}

Our further analysis showed that adolescent-reported CBCL scores were not significantly associated with parental work schedules (Appendix 2: Table 2). However, the effect of some of the covariates was consistent with the models of parent-reported CBCL scores. Drug use in the household showed a positive association with both externalizing behavior and total scores. Being male was associated with a lower internalizing behavior, 
anxiety/depression, and total morbidity scores. Mother's work hours were associated with higher total CBCL and externalizing scores. Higher maternal education was associated with lower total scores and lower anxiety/depression.

\section{Discussion}

Our findings show that when one or both parents worked NSW (unsociable and precarious) schedules, there was a significant increase in the parent-reported scores for total morbidity, externalizing and anxiety/depression, independent of the covariates. When analyzing both parent work schedules as interactions, we found that fathers’ NSW schedules were associated with higher CBCL score for total morbidity and externalizing behavior. When both parents worked NSW schedules, there was also an increase in all CBCL scores as expected, but the effect did not reach statistical significance, likely due to small subsample size (11\% (73) parents). Mothers' NSW schedules were not associated with higher adolescent CBCL scores. It is plausible that mothers working evening/night/irregular schedules during the week make up their time with adolescents on weekends. Mothers worked 15 hours less per week on average and spent more time with adolescents on weekends than fathers did (Table 1). Parental time with adolescents was associated with lower total morbidity and externalizing scores (Appendix 2: Table 3).

Our findings further demonstrate that the effect of fathers’ NSW schedules on adolescent mental health was partly mediated through inconsistent parenting on the part of the primary caregivers (mostly mothers). This suggests a spill-over effect of fathers’ work schedules onto the parenting behavior of mothers who worked standard schedules and in turn a negative effect on adolescent children. Similar spill-over effects were also reported by Kaiser et al. (Kaiser et al., 2019) in their study of younger children in Germany: strict and harsh parenting on the part of mothers partially mediated the effect of fathers working in evenings and nights on child conduct problems and vice versa, with a stronger effect of fathers' evening/night schedules and parenting on child social and emotional outcomes. Our results show that the number of hours both parents spent with their adolescents were associated lower total and externalizing scores, but they did not mediate the effect of NSW 
schedules on adolescent CBCL cores. The quality of time parents spend with children should be investigated in future research.

Our analysis did not show a significant association between parents’ work schedules and adolescentreported CBCL scores. The distribution of parent-reported and adolescent-reported CBCL scores differs considerably: parent-reported scores concentrated towards the lower end of the scale indicating less severe behavioral morbidity, whereas the adolescent-reported scores stretched more towards the higher end of the scale implicating more severe behavioral and emotional problems. The accuracy of reported child behavioral problems is determined by the saliency of behavioral problems to parents and children, and the willingness of both to report them (Karver, 2006). Our study suggests that the degree and types of behavioral morbidity may differ by parents’ observation and adolescents’ awareness of and willingness to report mental health issues they are faced with. Adolescents likely experience behavioral problems, such as binge drinking and experimenting with cigarettes and drugs outside the home, which parents may not be aware of. Such behavioral problems are more likely to be influenced by peer pressure than current parental work schedules. A longitudinal study of US adolescents (ages 13-14) showed that the number of years when mothers worked evening or night schedules was associated with increasing risk for drinking, smoking and drug use reported by the adolescents (Han et al., 2010). This suggests that longitudinal data are required in the future to understand the connection between joint parental NSW schedules and more severe mental morbidity in adolescents, such as risk-taking behaviors.

Our study has some limitations: 1) The study was cross-sectional due to the fact that data on parents’ work schedules were only collected at the follow up when children turned 16-17 years of age. Thus, the causal inference of parental NSW schedules cannot be established from our findings; 2) the sample size for the analysis was generally small and the effect of parental NSW schedules might have been underestimated, particularly for the category of both parents working NSW schedules with a low prevalence (11\%). The study also has several strengths. We have analyzed the CBCL scores based on both parents' and adolescents' reports, as experts recommend to use information from multiple informants when analyzing behavioral problems to minimize bias (Karver, 2006; Salbach-Andrae et al., 2009). Moreover, with the limited data available, we have explored and analyzed the data to its full potential. We examined both a binary indicator of work schedules and 
different categories of joint work schedules of both parents to reveal which combined work schedules were most strongly and negatively associated with adolescent mental wellbeing; we tested for mediation in a thorough manner and addressed possible reverse causality.

Previous studies have shown that joint parental work schedules matter for young children’s emotional and behavioural problems or academic performance, with a stronger negative effect of paternal evening/night work schedules (Han, 2020; Kaiser et al., 2019). Our findings corroborate with these previous studies on young children and demonstrate that joint work schedules in dual earner families are also important to adolescent children's social and emotional wellbeing, and that fathers' NSW schedules have a much more salient negative effect on adolescent children, relative to mothers’ NSW schedules. The findings from our study thus underscore the importance of understanding work-family interface among fathers and its impact on adolescent health and wellbeing. Current policy remains mainly focused on mothers' working hours and schedules and research in this field continues to concentrate primarily on young children. This focus needs to be broadened to include fathers’ work-family balance and its impact on adolescents in the future.

\section{References}

Achenbach, T. M., \& Edelbrock, C. S. (1991). The child behavior checklist manual. The University of Vermont. Andersen, S. L., \& Teicher, M. H. (2008). Stress, sensitive periods and maturational events in adolescent depression. Trends in Neurosciences, 31(4), 183-191. https://doi.org/10.1016/j.tins.2008.01.004

Australian Bureau of Statistics (ABS). (2009). Work, life and family balance, Australian social trends (6361.0; 4102.0 - Australian Social Trends). Australian Bureau of Statistics (ABS).

Australian Bureau of Statistics (ABS). (2019). Labour Force Status and Other Characteristics of Families (6224.0.55.001; Labour Force Status of Families). Australian Bureau of Statistics (ABS).

Bakker, A. B., Demerouti, E., \& Dollard, M. F. (2008). How job demands affect partners’ experience of exhaustion: Integrating work-family conflict and crossover theory. Journal of Applied Psychology, 93(4), 901911. https://doi.org/10.1037/0021-9010.93.4.901

Baron, R. M., \& Kenny, D. A. (1986). The Moderator-Mediator Variable Distinction in Social Psychological Research: Conceptual, Strategic, and Statistical Considerations. Journal of Personality and Social Psychology, 51(6), 1173-1182. 
Breusch, T. S., \& Pagan, A. R. (1979). A Simple Test for Heteroscedasticity and Random Coefficient Variation. Econometrica, 47(5), 1287. https://doi.org/10.2307/1911963

British Medical Association. (2006). Child and adolescent mental health: A guide for healthcare professionals. British Medical Association.

Brooks-Gunn, J., Brown, B., Duncan, G. J., \& Anderson Moore, K. (1995). Child Development in the Context of Family and Community Resources: An Agenda for National Data Collections. In National Research Council (US) \& Institute of Medicine (US) Board on Children and Families (Eds.), Integrating Federal Statistics on Children: Report of a Workshop (pp. 27-97). National Academies Press.

Dhaini, S. R., Denhaerynck, K., Bachnick, S., Schwendimann, R., Schubert, M., De Geest, S., \& Simon, M. (2018). Work schedule flexibility is associated with emotional exhaustion among registered nurses in Swiss hospitals: A cross-sectional study. International Journal of Nursing Studies, 82, 99-105. https://doi.org/10.1016/j.ijnurstu.2018.03.019

Dockery, A. M., Li, J., \& Kendall, G. (2009). Parents’ work patterns and adolescent mental health. Social Science \& Medicine, 68(4), 689-698. https://doi.org/10.1016/j.socscimed.2008.10.005

Dockery, A. M., Li, J., \& Kendall, G. (2016). Sole-parent work schedules and adolescent wellbeing:Evidence from Australia. Social Science \& Medicine, 168, 167-174. https://doi.org/10.1016/j.socscimed.2016.09.019

Greenhaus, J. H., \& Beutell, N. J. (1985). Sources of Conflict Between Work and Family Roles. Academy of Management Review, 10(1), 76-88. https://doi.org/10.5465/amr.1985.4277352

Han, W.-J. (2020). A first look at parental work schedules and children’s well-being in contemporary China. Community, Work \& Family, 23(3), 286-304. https://doi.org/10.1080/13668803.2018.1531826

Han, W.-J., \& Miller, D. P. (2009). Parental work schedules and adolescent depression. Health Sociology Review, 18(1), 36-49. https://doi.org/10.5172/hesr.18.1.36

Han, W.-J., Miller, D. P., \& Waldfogel, J. (2010). Parental work schedules and adolescent risky behaviors. Developmental Psychology, 46(5), 1245-1267. https://doi.org/10.1037/a0020178

Hayes, A. F. (2013). Introduction to mediation, moderation, and conditional process analysis: A regressionbased approach. The Guilford Press.

Hayes, A. F., \& Scharkow, M. (2013). The Relative Trustworthiness of Inferential Tests of the Indirect Effect in Statistical Mediation Analysis: Does Method Really Matter? Psychological Science, 24(10), 1918-1927. https://doi.org/10.1177/0956797613480187

Johnson, S., Li, J., Kendall, G., Strazdins, L., \& Jacoby, P. (2013). Mothers’ and Fathers’ Work Hours, Child Gender, and Behavior in Middle Childhood. Journal of Marriage and Family, 75(1), 56-74. https://doi.org/10.1111/j.1741-3737.2012.01030.x

Kaiser, T., Li, J., \& Pollmann-Schult, M. (2019). Evening and night work schedules and children’s social and emotional well-being. Community, Work \& Family, 22(2), 167-182.

https://doi.org/10.1080/13668803.2017.1404443 
Kantermann, T., Juda, M., Vetter, C., \& Roenneberg, T. (2010). Shift-work research: Where do we stand, where should we go? Sleep and Biological Rhythms, 8(2), 95-105. https://doi.org/10.1111/j.1479-8425.2010.00432.x

Karver, M. S. (2006). Determinants of Multiple Informant Agreement on Child and Adolescent Behavior. Journal of Abnormal Child Psychology, 34(2), 242-253. https://doi.org/10.1007/s10802-005-9015-6

Kendall, G. E., \& Li, J. (2005). Early childhood socialization and social gradients in adult health: A commentary on Singh-Manoux and Marmot's "Role of socialization in explaining social inequalities in health" (60: 9, 2005, 2129-2133). Social Science \& Medicine, 61(11), 2272-2276.

https://doi.org/10.1016/j.socscimed.2005.08.034

Lawrence, J. (2005). Young people in transition: Challenges and opportunities for contemporary Australian youth. In S. Richardson \& M. Prior (Eds.), No Time to Lose: The Wellbeing of Australia's Children (pp. 281296). Melbourne University Press.

Lempers, J. D., Clark-Lempers, D., \& Simons, R. L. (1989). Economic Hardship, Parenting, and Distress in Adolescence. Child Development, 60(1), 25. https://doi.org/10.2307/1131068

Li, J., Johnson, S. E., Han, W.-J., Andrews, S., Kendall, G., Strazdins, L., \& Dockery, A. M. (2014). Parents’ Nonstandard Work Schedules and Child Well-Being: A Critical Review of the Literature. The Journal of Primary Prevention, 35(1), 53-73. https://doi.org/10.1007/s10935-013-0318-z

McMenamin, T. M. (2007). A time to work: Recent trends in shift work and flexible schedules. Monthly Labor Review, 130(12), 3-15.

Messenger, J. (2018). Working time and the future of work (No. 6; ILO Future of Work Paper Series, p. 44). International Labour Office.

Moreno, C. R. C., Marqueze, E. C., Sargent, C., WRIGHT Jr, K. P., Ferguson, S. A., \& Tucker, P. (2019). Working Time Society consensus statements: Evidence-based effects of shift work on physical and mental health. Industrial Health, 57(2), 139-157. https://doi.org/10.2486/indhealth.SW-1

Newnham, J. P., Evans, S. F., Michael, C. A., Stanley, F. J., \& Landau, L. I. (1993). Effects of frequent ultrasound during pregnancy: A randomised controlled trial. The Lancet, 342(8876), 887-891. https://doi.org/10.1016/0140-6736(93)91944-H

Pokhrel, P., Herzog, T. A., Black, D. S., Zaman, A., Riggs, N. R., \& Sussman, S. (2013). Adolescent Neurocognitive Development, Self-Regulation, and School-Based Drug Use Prevention. Prevention Science, 14(3), 218-228. https://doi.org/10.1007/s11121-012-0345-7

Preacher, K. J., \& Hayes, A. F. (2008). Asymptotic and resampling strategies for assessing and comparing indirect effects in multiple mediator models. Behavior Research Methods, 40(3), 879-891.

https://doi.org/10.3758/BRM.40.3.879

Presser, H. B. (2003). Working in a 24/7 economy: Challenges for American families. Russell Sage Foundation.

Rosenbaum, E., \& Morett, C. R. (2009). The Effect of Parents’ Joint Work Schedules on Infants’ Behavior Over the First Two Years of Life: Evidence from the ECLSB. Maternal and Child Health Journal, 13(6), $732-744$. https://doi.org/10.1007/s10995-009-0488-8 
Salbach-Andrae, H., Lenz, K., \& Lehmkuhl, U. (2009). Patterns of agreement among parent, teacher and youth ratings in a referred sample. European Psychiatry, 24(5), 345-351. https://doi.org/10.1016/j.eurpsy.2008.07.008

Squeglia, L. M., Jacobus, J., \& Tapert, S. F. (2009). The Influence of Substance Use on Adolescent Brain Development. Clinical EEG and Neuroscience, 40(1), 31-38. https://doi.org/10.1177/155005940904000110

Straker, L., Mountain, J., Jacques, A., White, S., Smith, A., Landau, L., Stanley, F., Newnham, J., Pennell, C., \& Eastwood, P. (2017). Cohort Profile: The Western Australian Pregnancy Cohort (Raine) Study-Generation 2. International Journal of Epidemiology, 1384-1385j. https://doi.org/10.1093/ije/dyw308

Strazdins, L., Clements, M. S., Korda, R. J., Broom, D. H., \& D’Souza, R. M. (2006). Unsociable Work? Nonstandard Work Schedules, Family Relationships, and Children's Well-Being. Journal of Marriage and Family, 68(2), 394-410. https://doi.org/10.1111/j.1741-3737.2006.00260.x

Zubrick, S. R., Silburn, S., Gurrin, L., Teoh, H., Shepherd, C. C., Carlton, J., \& Lawrence, D. (1997). Western Australian child health survey: Education, health and competence. Australian Bureau of Statistics: TVW Telethon Institute for Child Health Research. 
Table 1

Descriptive statistics for all study variables for the study population (two-parent families with working parent(s))

\begin{tabular}{|c|c|c|c|c|c|}
\hline & $\mathrm{n}=662$ & $\%$ & Mean (SD) & Min & Max \\
\hline Parent-reported CBCL scores & 645 & 97.43 & & & \\
\hline Missing (for total score and all subdomains) & 17 & 2.57 & & & \\
\hline Total score & 645 & & $11.60(12.71)$ & 0 & 85 \\
\hline Externalizing behavior score & 645 & & $4.20(5.66)$ & 0 & 34 \\
\hline Internalizing behavior score & 645 & & $3.73(4.68)$ & 0 & 32 \\
\hline Anxiety depression score & 645 & & $1.71(2.60)$ & 0 & 18 \\
\hline Adolescent birthweight & 661 & 99.85 & $3361.34(550.77)$ & 1020 & 5185 \\
\hline Missing & 1 & 0.15 & & & \\
\hline Father's work hours & 658 & & $45.53(12.82)$ & 0 & 100 \\
\hline Missing & 4 & 0.60 & & & \\
\hline Mother's work hours & 660 & & 30.35 (13.67) & 2 & 100 \\
\hline Missing & 2 & 0.30 & & & \\
\hline Dichotomous parent work schedules & 662 & & & & \\
\hline Both parents - standard & 331 & 50.00 & & & \\
\hline One or both parents - nonstandard & 331 & 50.00 & & & \\
\hline Categorical parent work schedules & 662 & & & & \\
\hline Both parents - standard & 331 & 50.00 & & & \\
\hline Both parents - nonstandard & 73 & 11.03 & & & \\
\hline Father - nonstandard/Mother - standard & 114 & 17.22 & & & \\
\hline Mother - nonstandard/Father - standard & 144 & 21.75 & & & \\
\hline Gender & 662 & & & & \\
\hline Girl & 314 & 47.43 & & & \\
\hline Boy & 348 & 52.57 & & & \\
\hline Drug use in home - total & 661 & & & & \\
\hline No & 598 & 90.47 & & & \\
\hline Yes & 63 & 9.53 & & & \\
\hline Missing & 1 & 0.15 & & & \\
\hline Mother's age at 18 weeks pregnancy & 662 & & & & \\
\hline $14-24$ (ref.) & 110 & 16.62 & & & \\
\hline $25-29$ & 203 & 30.66 & & & \\
\hline $30-34$ & 233 & 35.20 & & & \\
\hline 35 or over & 116 & 17.52 & & & \\
\hline Mother's race & 662 & & & & \\
\hline Caucasian & 610 & 92.15 & & & \\
\hline Other & 52 & 7.85 & & & \\
\hline Mother's education & 634 & & & & \\
\hline Primary education & 101 & 15.93 & & & \\
\hline Secondary or higher & 533 & 84.07 & & & \\
\hline Missing & 28 & 4.23 & & & \\
\hline Mother's occupation & 662 & & & & \\
\hline Manager or professional & 248 & 37.46 & & & \\
\hline Paraprofessional, clerical, or sales & 368 & 55.59 & & & \\
\hline Trade, plant operator, or labourer & 46 & 6.95 & & & \\
\hline Father's occupation & 657 & & & & \\
\hline Manager & 107 & 16.29 & & & \\
\hline Professional & 200 & 30.44 & & & \\
\hline Paraprofessional, clerical, or sales & 160 & 24.35 & & & \\
\hline
\end{tabular}




\begin{tabular}{|c|c|c|c|c|c|}
\hline Trade & 105 & 15.98 & & & \\
\hline Plant operator or labourer & 85 & 12.94 & & & \\
\hline Missing & 5 & 0.76 & & & \\
\hline Time mother spent with adolescent on weekends & 662 & & & & \\
\hline None & 5 & 0.76 & & & \\
\hline$<1$ hour & 60 & 9.06 & & & \\
\hline $1-6$ hours & 470 & 71.00 & & & \\
\hline $6-10$ hours & 100 & 15.11 & & & \\
\hline $11-20$ hours & 21 & 3.17 & & & \\
\hline Missing & 6 & 0.91 & & & \\
\hline Time father spent with adolescent on weekends & 662 & & & & \\
\hline None & 27 & 4.08 & & & \\
\hline$<1$ hour & 81 & 12.24 & & & \\
\hline $1-6$ hours & 343 & 51.81 & & & \\
\hline $6-10$ hours & 66 & 9.97 & & & \\
\hline $11-20$ hours & 14 & 2.11 & & & \\
\hline Missing & 131 & 19.79 & & & \\
\hline Parenting style score - nurturing & 662 & & & & \\
\hline Valid & 539 & 81.42 & $1.97(0.76)$ & 0 & 3 \\
\hline Missing & 123 & 18.58 & & & \\
\hline Parenting style score - inconsistent & 662 & & & & \\
\hline Valid & 537 & 81.12 & $1.14(0.57)$ & 0 & 3 \\
\hline Missing & 125 & 18.88 & & & \\
\hline
\end{tabular}


Table 2

Multivariate linear regression analysis of log-transformed CBCL scores (parent-reported), $\mathrm{N}=607$

\begin{tabular}{|c|c|c|c|}
\hline & Total score $^{1}$ & Externalizing score & Internalizing score \\
\hline \multicolumn{4}{|l|}{ Parent work schedules (dichotomous) ${ }^{3}$} \\
\hline Both parents - standard & $0()$. & $0()$. & $0()$. \\
\hline One or both parents - nonstandard & $.198 *(.088)$ & $.181 *(.076)$ & $.145(.074)$ \\
\hline \multicolumn{4}{|l|}{ Parent work schedules (categorical) } \\
\hline Both parents - standard & $0()$. & $0()$. & $0()$. \\
\hline Both parents - nonstandard & $.161(.149)$ & $.183(.129)$ & $.149(.127)$ \\
\hline Father - nonstandard / Mother - standard & $.353 * *(.123)$ & $.306^{* *}(.107)$ & $.154(.104)$ \\
\hline Mother - nonstandard / Father - standard & $.097(.112)$ & $.085(.097)$ & $.067(.095)$ \\
\hline Fathers' work hours & $-.006(.004)$ & $-.002(.003)$ & $-.004(.003)$ \\
\hline Mothers’ work hours & $.005(.003)$ & $.005^{*}(.003)$ & $.003(.003)$ \\
\hline Gender (boy) & $-.015(.089)$ & $.082(.077)$ & $-.247 * *(.076)$ \\
\hline Adolescent birthweight & $0.00(0.00)$ & $0.00(0.00)$ & $0.00(0.00)$ \\
\hline Drug use in the home & $.354 *(.146)$ & $.35^{* *}(.127)$ & $.137(.124)$ \\
\hline \multicolumn{4}{|l|}{ Mother's age (18 weeks pregnant) } \\
\hline $14-24$ (ref.) & $0()$. & $0()$. & $0()$. \\
\hline $25-29$ & $-.038(.136)$ & $-.072(.118)$ & $-.095(.116)$ \\
\hline $30-34$ & $-.181(.136)$ & $-.24 *(.119)$ & $-.178(.116)$ \\
\hline 35 or over & $-.147(.152)$ & $-.267 *(.132)$ & $-.072(.129)$ \\
\hline Mother's race & $.073(.164)$ & $.037(.142)$ & $-.047(.139)$ \\
\hline \multicolumn{4}{|l|}{ Mother's education } \\
\hline Primary education & $0()$. & $0()$. & $0()$. \\
\hline Secondary or higher & $-.127(.126)$ & $-.147(.11)$ & $-.097(.108)$ \\
\hline \multicolumn{4}{|l|}{ Mother's occupation } \\
\hline Manager or professional & $0()$. & $0()$. & $0()$. \\
\hline Paraprofessional, clerical, or sales & $.063(.101)$ & $.021(.088)$ & $.085(.086)$ \\
\hline Trade, plant operator, or labourer & $-.274(.188)$ & $-.205(.163)$ & $-.183(.16)$ \\
\hline \multicolumn{4}{|l|}{ Father's occupation } \\
\hline Manager & $0()$. & $0()$. & $0()$. \\
\hline Professional & $.008(.136)$ & $.068(.118)$ & $-.093(.116)$ \\
\hline Paraprofessional, clerical, or sales & $-.002(.142)$ & $-.074(.124)$ & $.022(.121)$ \\
\hline Trade & $-.091(.155)$ & $.075(.135)$ & $-.179(.132)$ \\
\hline Plant operator or labourer & $.133(.17)$ & $.274(.148)$ & $-.03(.144)$ \\
\hline Constant & $2.018^{* * *}(.429)$ & $1.007 * *(.373)$ & $1.519 * * *(.365)$ \\
\hline $\mathrm{R}^{2}$ & 0.054 & 0.077 & 0.052 \\
\hline
\end{tabular}

* $\mathrm{p}<0.05, * * \mathrm{p}<0.01, * * * \mathrm{p}<0.001$

1 Unstandardized coefficient and standard errors in parentheses.

2 This subdomain is modelled using robust standard errors to address the marginal heteroskedasticity that remained after natural log transformation.

${ }^{3}$ Dichotomous indicator of parental work schedules was tested in separate models using the same set of control variables.

Table 3

Mediation effect of parenting on log-transformed Total CBCL Score (parent-reported) for fathers' nonstandard work schedule, $\mathrm{N}=565$

\begin{tabular}{lc}
\hline & Total CBCL Score (Bootstrap SEs) \\
\hline Inconsistent Parenting Style & \\
\hline Mother works nonstandard work schedule & $-.036(.134)$ \\
$\quad$ Direct effect ${ }^{1}$ & $.009(.020)$ \\
$\quad$ Indirect effect $^{2}$ &
\end{tabular}


Direct effect

Indirect effect

Both parents work nonstandard work schedule

Direct effect

Indirect effect
$.291 *(.127)$

$.044 *(.029)$

$.123(.179$

$.038(.029)$

Effect of inconsistent parenting on Total CBCL score ${ }^{3}$

$.302 * *(.057)$

Notes: Controls: Adolescent gender; mother's age at 18 weeks pregnancy; mother's race; mother's educational attainment; drug use in home; adolescent birthweight; mother's occupation; father's occupation; mother's work hours; father's work hours. Significance of indirect effects obtained from $95 \%$ bootstrap bias-corrected confidence intervals. ${ }^{*} \mathrm{p}<0.05$, ${ }^{* *} \mathrm{p}<0.01$, $* * * \mathrm{p}<0.001$

${ }^{1}$ Refers to direct effect of parents' nonstandard work schedules on adolescent CBCL scores.

${ }^{2}$ Refers to indirect effect of parents' nonstandard work schedules on adolescent CBCL scores via inconsistent parenting mediation pathway. Note that direct effect and indirect effect sum to equal the total effect. However, since mediation effects were estimated in a model separate from the main models reported in Table 2, there is an infinitesimal difference between total effects as reported in Table 2 and the sum of direct and indirect effects reported in Tables 3 and 4.

${ }^{3}$ Refers to effect of mediator on adolescent CBCL scores; the intermediate step of establishing mediation. 